\title{
Correction to: Experienced HIV-Related Stigma and Psychological Distress in Peruvian Sexual and Gender Minorities: A Longitudinal Study to Explore Mediating Roles of Internalized HIV-Related Stigma and Coping Styles
}

\author{
Rachel Rinehart ${ }^{1}$. Deepa Rao ${ }^{2} \cdot$ Rivet K. Amico $^{3}$. Eduardo Ruiz ${ }^{4}$ Peter Brandes ${ }^{4}$. Cecilia Correa ${ }^{4}$ Siavash Pasalar ${ }^{1}$. \\ Javier R. Lama ${ }^{4} \cdot$ Ann Duerr ${ }^{1,2} \cdot$ Yamile Molina ${ }^{1,5}$
}

Published online: 7 February 2019

(c) Springer Science+Business Media, LLC, part of Springer Nature 2019

\section{Correction to: AIDS and Behavior https://doi.org/10.1007/s10461-018-2348-2}

In the original publication of the article, the given name of the second author was not correct. The name has been corrected with this erratum.

Publisher's Note Springer Nature remains neutral with regard to jurisdictional claims in published maps and institutional affiliations.

The original article can be found online at https://doi.org/10.1007/ s10461-018-2348-2.

Yamile Molina

ymolin2@uic.edu

Fred Hutchinson Cancer Research Center, Seattle, USA

2 Department of Global Health, University of Washington, Seattle, USA

3 Department of Health Behavior and Health Education, University of Michigan, Ann Arbor, USA

4 La Asociación Civil Impacta Salud y Educación, Lima, Peru

5 Division of Community Health Sciences, University of Illinois at Chicago, 1603 West Taylor Street, Room 649, Chicago, IL 60612, USA 